\title{
Clinical utility of etanercept in the treatment of arthritides in children and adolescents
}

This article was published in the following Dove Press journal:

Adolescent Health, Medicine and Therapeutics

26 March 2014

Number of times this article has been viewed

\section{Robin K Dore}

David Geffen School of Medicine, Division of Rheumatology, UCLA, Los Angeles, CA, USA
Correspondence: Robin K Dore Clinical Professor of Medicine, David Geffen School of Medicine, Division of Rheumatology,

I279| Newport Ave \#20 I,

Tustin, CA, USA 92780, UCLA, Los Angeles, CA, USA

Tel + I $7 \mid 45055500$

Fax + $7 \mid 4505338$

Email drdore@robinkdoremd.com
Abstract: Juvenile idiopathic arthritis (JIA) is a group of chronic inflammatory diseases affecting approximately 300,000 children and adolescents in the United States of unknown cause. It can affect children from the age of 0 years up to the age of 16 years. The International League of Associations of Rheumatology has defined seven subsets of JIA based on several factors including the number of affected joints and the involvement of other tissues; the prognosis for each affected child also depends on multiple factors including age of onset, number of joints involved, and systemic features. As with rheumatoid arthritis in adults, the goal of therapy is remission and resolution of disease activity; however, as a cure does not seem attainable in the near future, a reasonable goal of therapy is prevention of joint damage, inhibition of inflammation, and a high level of quality of life. Even with available therapies, many children with JIA enter adulthood with persistently active disease, suboptimal function, and impaired quality of life. Methotrexate remains the standard of care for children with JIA; etanercept was approved in 2000 in the United States for the treatment of JIA resistant to methotrexate. The efficacy and safety of etanercept therapy in children with JIA is reviewed and its place in the therapeutic regimen is discussed; the available long term data is also presented. The data presented was obtained from a PubMed search as well as a review of the references presented in the 2011 American College of Rheumatology Recommendations for the Treatment of Juvenile Idiopathic Arthritis and the 2013 Update. It is hoped that treatment with etanercept and other biologic therapies will lead to improved outcomes for children with JIA in the future.

Keywords: juvenile idiopathic arthritis, juvenile chronic arthritis, juvenile rheumatoid arthritis, etanercept

\section{Introduction}

Juvenile idiopathic arthritis (JA), called juvenile rheumatoid arthritis in the past, is the most common form of arthritis in children and adolescents, affecting over 300,000 individuals in the US. ${ }^{1}$ It is a heterogeneous group of inflammatory arthritides that occur in children younger than 16 years of age with no defined cause. The revised International League of Associations for Rheumatology classification defines seven subsets of JIA including systemic-onset JIA, persistent or extended oligoarthritis, rheumatoid factor (RF)-negative polyarthritis, RF-positive polyarthritis, psoriatic JIA, enthesitis-related arthritis, and undifferentiated. ${ }^{2}$ Systemic JIA is diagnosed if there is arthritis in one or more joints associated with a fever of at least 2 weeks duration; signs and symptoms must have been present daily for at least 3 days and associated with one or more of the following: evanescent rash, serositis, hepatosplenomegaly, and generalized lymphadenopathy. Persistent or extended oligoarticular JIA is diagnosed if there is synovitis in one to four 
joints within 6 months of disease onset; the persistent type can affect up to four joints during the course of the disease and the extended type affects more than four joints after the first 6 months of the disease. RF-negative JIA is diagnosed if the RF is negative during the first 6 months of the disease and five or more joints are affected. RF-positive JIA is diagnosed if the RF is positive during the first 6 months of the disease and five or more joints are affected. Psoriatic JIA is diagnosed if both psoriasis and arthritis are present or arthritis and at least two of the following are present: nail pitting, dactylitis, family history of psoriasis in a first-degree relative, and/or onycholysis. Enthesitis-related JIA is diagnosed if arthritis and at least two of the following are present: positive $H L A-B 27$ gene, acute symptomatic anterior uveitis, enthesitis-related arthritis, Reiter's syndrome, sacroiliitis with inflammatory bowel disease, onset of arthritis in a male over the age of 6 years, presence or history of sacroiliac joint tenderness with or without inflammatory low back pain, acute anterior uveitis in a first-degree relative or a history of ankylosing spondylitis. Undifferentiated JIA is diagnosed if there is arthritis that does not meet the criteria in any of the categories listed above or that fulfills criteria from two or more of the categories listed above. Understanding the different subgroups is important as treatment and response to therapy varies among the different subgroups.

The American College of Rheumatology published recommendations for the treatment of JIA in 2011 and these were updated in 2013, but the most recent update only includes recommendations for the medical therapy of children with systemic JIA and tuberculosis screening among children receiving biologic medications. ${ }^{3,4}$ These recommendations divide JIA into "treatment groups" rather than using the categories of JIA defined above by the International League of Associations of Rheumatology. Also, many of the recommendations "fall outside the present bounds of regulatory agency approved labeling," meaning that they include recommendations to use therapies "off-label" that reflect standards of care in pediatric rheumatology. The recommendations cover the initiation and safety monitoring of therapeutic agents used in treating JIA including non-steroidal anti-inflammatory drugs (NSAIDs), intra-articular glucocorticoid injections, non-biologic disease modifying anti-rheumatic drugs (DMARDs), biologic DMARDs, and systemic glucocorticoids for the treatment of the systemic features of systemic JIA.

Many children respond to therapies including NSAIDs, glucocorticoids (intra-articular, oral, or pulsed intravenously), and non-biologic DMARDs, of which methotrexate is the most commonly prescribed. ${ }^{5}$ Methotrexate is recommended to be used in children with a history of arthritis of four or fewer joints only if they have failed NSAIDs and intra-articular glucocorticoid injections. In children with JIA affecting five or more joints, methotrexate is recommended if a child has failed 1-2 months of an NSAID, and in systemic JIA with active arthritis, methotrexate is recommended after a 1 month trial of an NSAID in addition to glucocorticoid joint injections on an as needed basis. In systemic JIA without active arthritis if a child has failed NSAIDs after 2 weeks, systemic glucocorticoids followed by biologic DMARDs are the recommendation. Biologic DMARDs are recommended for use in patients with JIA affecting four or fewer and five or more joints only after failing 3-6 months of methotrexate; tumor necrosis factor (TNF)-alpha inhibitors are recommended as initial biologic therapy followed by a second TNF-alpha inhibitor or abatacept. The biologic therapies recommended for systemic JIA in children with active systemic features and varying degrees of synovitis include an interleukin (IL)-1 inhibitor (anakinra) followed by an IL-6 inhibitor (tocilizumab) followed by abatacept. Canakinumab is recommended for children with continued disease activity after treatment with glucocorticoids, methotrexate, or leflunomide, anakinra, or tocilizumab. Initiation of a TNF-alpha inhibitor was recommended only after a trial of an IL-1 inhibitor and/or tocilizumab. For systemic JIA without active systemic features but with varying degrees of active synovitis, the recommendations are to begin with intra-articular glucocorticoids, followed by methotrexate or leflunomide, then anakinra, tocilizumab, and then abatacept. In this group, canakinumab was only recommended for patients who have had a trial of a non-biologic DMARD plus anakinra or tocilizumab, a non-biologic DMARD plus a TNFalpha inhibitor, or abatacept. For active sacroiliac arthritis, initiation of TNF-alpha inhibitor therapy is recommended after failure of 3-6 months of methotrexate or sulfasalazine. Unlike in adult rheumatoid arthritis, biologic therapy is often given as monotherapy rather than as combination therapy (with a non-biologic DMARD), although this is becoming a more common practice based on results of the TREAT study that will be discussed below. ${ }^{6}$ This manuscript reviews data concerning the pharmacology, efficacy, safety, and use of etanercept in children and young adults; the author did not participate in any of the studies referenced.

\section{Pharmacology of etanercept with reference to children and adolescents}

A biologic DMARD describes a class of drugs given parenterally that have been designed to have "biologic properties" and 
include recombinant receptor antagonists, soluble cytokine inhibitors, and monoclonal antibodies. These include drugs that block TNF-alpha such as infliximab, etanercept, adalimumab, certolizumab, and golimumab in addition to other agents such as anakinra (IL-1 inhibitor), tocilizumab (IL-6 inhibitor), abatacept (a selective T cell co-stimulation modulator), and rituximab (a CD20-directed cytolytic antibody). TNF is a naturally occurring cytokine that plays an active role in normal inflammatory and immune responses. It also has an important role in the inflammatory processes of rheumatoid arthritis, polyarticular JIA, psoriatic arthritis, and ankylosing spondylitis and the resulting joint damage, and in the inflammatory process of psoriasis. Elevated levels of TNF-alpha, IL-2, IL-6, interferon beta, and interferon gamma are found in the involved tissues and joint fluids of patients with JIA; elevated levels of IL-1 alpha are also found in the synovial fluid of patients with JIA with corresponding impaired production of anti-inflammatory cytokines. ${ }^{\text {? }}$ Cytokine levels have been reported to correlate with disease activity including soluble TNF receptor (TNFR) levels. ${ }^{8}$ Two separate TNFRs exist - a $55 \mathrm{kDa}$ protein (p55) and a $75 \mathrm{kDa}$ protein (p75); these occur naturally as monomeric molecules on cell surfaces and in soluble forms. The biologic activity of TNF is dependent on binding to either of the cell surface TNFRs; etanercept and adalimumab are the TNF-alpha inhibitors approved for treating JIA in the United States, the $\mathrm{UK}$, and the EU and infliximab is approved in the UK for the treatment of JIA.

The first TNF-alpha inhibitor approved in the US for treatment of polyarticular JIA refractory to methotrexate therapy was etanercept. Etanercept is a dimeric soluble form of the $\mathrm{p} 75$ TNFR that binds TNF molecules; it inhibits binding of TNF-alpha and TNF-beta to cell surface TNFRs, inactivating TNF. ${ }^{9}$ Etanercept is indicated for reducing the signs and symptoms of moderately to severely active polyarticular JIA in children ages 2 years and older. It is not indicated for the treatment of juvenile spondyloarthropathy, but data are available from an open-label Phase IIIb study, other open-label studies, registries, retrospective studies, and case reports. It is on this basis that the American College of Rheumatology recommends use of etanercept in this subtype of JIA even though it is not an approved indication.

\section{Etanercept efficacy}

Trials of etanercept and other biologic therapies were conducted as a result of the 1999 Pediatric Rule requiring pharmaceutical companies to test biologic agents in children with JIA simultaneously with the trials in adults. At present, etanercept is marketed in 100 countries for the treatment of JIA, starting in 1999. The initial trials of etanercept treatment in adults with established rheumatoid arthritis enrolled 714 patients; the initial trial of etanercept in children with JIA enrolled 69 children aged 4-17 years who did not tolerate or had an inadequate response to methotrexate. ${ }^{10}$ Lovell et al performed an open-label trial of etanercept $0.4 \mathrm{mg}$ per kilogram of body weight subcutaneously two times a week for up to 3 months, followed by a double-blind study of etanercept or placebo for 4 months or until a flare of the disease occurred. ${ }^{10}$ Fifty-one of the 69 patients enrolled in the open-label study (74\%) met the definition of improvement at the end of that part of the study; 44 of the 69 patients (64\%) met the definition of $50 \%$ improvement and $25(36 \%)$ met the definition of $70 \%$ improvement at the end of the open-label part of the study. At the end of the study, $72 \%$ of the etanercept ( 18 patients) and $23 \%$ of the placebo patients (six patients) met the definition of $50 \%$ improvement. Forty-four percent of the etanercept (eleven patients) and 19\% of the placebo (five patients) met the definition of $70 \%$ improvement. Measures of disease activity continued to improve in the etanercept patients during the double-blind part of the study, whereas disease activity increased in the placebo patients. At the end of the trial, 58 of the original 69 patients entered an openlabel extension; glucocorticoids and NSAIDs were allowed during the randomized trial and the open-label extension, but very few patients were allowed to re-initiate methotrexate. ${ }^{10}$ In the open-label extension, 42 of the original patients $(61 \%)$ received at least 4 years of etanercept and $16(23 \%)$ received at least 8 years of continuous etanercept. Etanercept did not result in drug-free remission; over time many patients received non-biologic DMARDs, including methotrexate or glucocorticoids. At baseline, patients were not allowed to take DMARD therapy, but during the 8 years, 53\% of the patients received one or more DMARDs, of which $38 \%$ were on methotrexate. Twenty-nine percent of patients were taking glucocorticoids at the beginning of the open-label extension, but $60 \%$ of patients received glucocorticoids at some time during the 8 years of follow-up. Sixteen patients (23\%) reported adverse events. After 4-8 years of follow-up, one severe adverse event of pyelonephritis occurred; there were no cases of lupus, demyelinating disorders, tuberculosis or other opportunistic infections, malignancy, or death. ${ }^{11}$ Three cases of varicella, however, occurred during the follow-up; as a result, the authors suggested that all children be tested for varicella antibodies before starting treatment with etanercept and that extra precautions should be taken to avoid 
exposing non-immune children on etanercept to those with active varicella disease.

As a result of the data provided by this one study, the National Institute for Health and Care Excellence in the UK published guidance on the use of etanercept for the treatment of JIA. ${ }^{12}$ This document recommended etanercept therapy for children aged 4-17 years with active polyarticular-course JIA whose condition has not responded to, or who have been unable to tolerate, methotrexate. This document states that etanercept may be given for an indefinite period of time, but recommends that once a child with JIA has had two disease-free years that the treatment be stopped, although it would be expected that $30 \%$ of children would be expected to relapse.

Schmeling et al studied a combination of etanercept and methotrexate for the treatment of refractory JIA. ${ }^{13}$ This openlabel study enrolled seven children who were not responsive to a combination of methotrexate and sulfasalazine or cyclosporine A; they were allowed to continue on their NSAIDs, glucocorticoids, and methotrexate. Six out of seven children continued the combination treatment for at least 24 weeks; one child with systemic arthritis stopped etanercept due to fever, joint pain, and rash. In the six children who remained on therapy, improvement was seen after two injections in joint pain, morning stiffness, and joint swelling. Markers of inflammation including erythrocyte sedimentation rate (ESR), C reactive protein, and IL-6 were reduced. Two children had mild injection site reactions.

Kietz et al presented data concerning the use of etanercept in an open-label study in polyarticular JIA over a 2-year period of time in 22 children. ${ }^{14}$ At study entry, 21/22 of the children were receiving methotrexate at a dose of at least $10-15 \mathrm{mg} / \mathrm{m}^{2}$ body surface area with duration of methotrexate treatment ranging from 6 months to 16 years; these doses of methotrexate were continued during the open-label study. All of the patients were on NSAIDs, 13/22 patients were receiving hydroxychloroquine, one patient was on sulfasalazine, five were receiving low dose glucocorticoids, and nine additional patients had received glucocorticoids in the past. At study onset, all patients were started on etanercept $0.4 \mathrm{mg} / \mathrm{kg}$ two times weekly. At the time of publication, the mean duration of treatment with etanercept was 16.7 months with a range of 4-26 months; the median duration of treatment was 21 months with eight patients being treated for 24 months or longer. Evaluation at these time points revealed a mean individual percentage decrease in swollen joints of $49 \%$, a mean percentage decrease in tender joints of $94 \%$, the duration of morning stiffness decreased to less than 10 minutes or was not present and complains of fatigue significantly improved. Inflammatory markers also improved with an average reduction in ESR of $42 \mathrm{~mm}$ (range 2-124 $\mathrm{mm}$ ) with a mean percentage decrease of $64 \%$ and the hemoglobin had an average increase of $1.4 \mathrm{~g} / \mathrm{dL}$ with a mean individual percentage increase of $15.29 \%$. Mild injection site reactions occurred but no serious infections were reported. In most patients, the dose of glucocorticoids was reduced or stopped and many patients no longer required NSAID therapy. Of note, no attempt was made to reduce the dose of methotrexate or etanercept once a treatment response had occurred.

Haapasaari et al studied the addition of etanercept to prevailing DMARD therapy in refractory JIA. ${ }^{15}$ At that time, methotrexate was considered the gold standard to treat JIA with a response rate of $60 \%-80 \%$ at doses of $15-20 \mathrm{mg} / \mathrm{m}^{2}$ body surface area weekly. ${ }^{16}$ In this study, children who did not respond to methotrexate were treated with etanercept at a dose of $0.4 \mathrm{mg} / \mathrm{kg}$ twice per week and followed for 1 year. Six of the children had oligoarticular JIA, 22 had polyarticular JIA, and three had systemic JIA. The mean age was 10 years of age (range $3-15$ years) and mean disease duration was 6 years (range 1-14 years). At initiation of etanercept, $28(90 \%)$ children were treated with a combination of two or more DMARDs and three received only one DMARD. All but one of the children were treated with glucocorticoids with a mean dose of $16.3 \mathrm{mg}$ (range $0-45 \mathrm{mg}$ ) every other day. At the 1-year data point, a positive treatment effect was seen with statistically significant reductions in ESR and C reactive protein, reduction in the dose of glucocorticoids, reduction in the number of intra-articular steroid injections, and reduction in the number of inpatient hospitalizations. Direct median costs of treating JIA increased during the first 3 months of etanercept therapy, but decreased later during the follow-up period. The estimated median direct costs per child increased by $\$ 4,200$ (US dollars) per year, but the indirect costs were reduced by $\$ 1,700$, a $50 \%$ reduction. Therefore, the estimated median total cost per child was increased by about $\$ 2,700$ (10\%) per year. The authors concluded that this minimal increase in the yearly cost of treating JIA should be evaluated in light of the reduced inflammatory joint disease and the probable reduction in pain and disability over the many years of the children's lives.

Giannini et al also studied combination therapy in treating JIA, but rather than a single arm study, these authors studied treatment with methotrexate alone, etanercept alone, or etanercept plus methotrexate in an open-label, 3-year study; study sites were in the US and Canada. ${ }^{17}$ Children aged $2-18$ years were entered in the study with systemic, oligoarticular, or 
polyarticular JIA; three children less than 2 years of age were also included in the study. Children were required to have had an adequate trial of NSAIDs and/or glucocorticoids prior to study entry. At study entry, children were required to have at least three active joints or inactive disease treated with one or more DMARDs or etanercept. At study entry, children were receiving one of the following therapies with or without other DMARDs: sulfasalazine, methotrexate, cyclosporine, leflunomide, injectable gold, hydroxychloroquine, and azathioprine. Children enrolled in the methotrexate arm could switch to etanercept or etanercept plus methotrexate treatment and re-enroll into the etanercept or etanercept plus methotrexate arms within 30 months of enrollment. Children who stopped etanercept and started methotrexate therapy were not re-enrolled. A total of 198 children received methotrexate, 105 received etanercept, and 299 received the methotrexateetanercept combination. A total of 66 methotrexate (33\%), 33 etanercept (31\%), and 105 etanercept-methotrexate (35\%) treated children completed the 3 -year registry. Withdrawal from the study included $18 \%$ of the methotrexate group, $8 \%$ of the etanercept group, and $19 \%$ of the etanerceptmethotrexate group due to insufficient therapeutic effect; in addition, $2 \%$ of the methotrexate, $2 \%$ of the etanercept, and $0.3 \%$ of the etanercept-methotrexate treated children stopped the study due to adverse events. In addition, $12 \%$ of the methotrexate, $6 \%$ of the etanercept, and $4 \%$ of the etanercept-methotrexate treated children stopped the study as their disease had gone into remission. Rates of serious adverse events per 100 patient-years were 4.4 for methotrexate, 7.6 for etanercept, and 5.7 for etanercept-methotrexate treated children. Improvements in outcome measures were similar among all three treatment groups and were maintained at 3 years. The authors concluded that "these data suggest etanercept is safe as a long-term, continuous therapy for [the] treatment of juvenile rheumatoid arthritis".

Wallace et al performed a multicenter, prospective, double-blind, randomized, placebo-controlled trial of two "aggressive" treatments in 85 children aged 2-16 years with polyarticular JIA of less than 1 year duration. ${ }^{6}$ Children received either methotrexate $0.5 \mathrm{mg} / \mathrm{kg} /$ week subcutaneously, etanercept $0.8 \mathrm{mg} / \mathrm{kg} /$ week, and prednisolone $0.5 \mathrm{mg} / \mathrm{kg} /$ day tapered to $0 \mathrm{mg}$ by 17 weeks (arm 1) or methotrexate, etanercept placebo, and prednisolone placebo (arm 2). The primary outcome was clinically inactive disease at 6 months, which is defined as no joints with active arthritis, no fever, no rash, no serositis, no splenomegaly or generalized lymphadenopathy, no active uveitis, ESR in the normal range, and physician's assessment of disease activity of zero. Forty-two children were randomized to arm 1 and 43 children to arm 2. Twenty-two males and 63 females with a mean age of 10.5 years and a mean disease duration of 5.1 months were enrolled in the study. Children who failed to meet endpoints in the pivotal phase (first 6 months) were given open-label arm 1 medications during the second 6 months. By 6 months, clinically inactive disease had been achieved in 17 children (40\%) in arm 1 and in ten children (23\%) in arm 2. After 1 year, clinical remission on medications was achieved in nine children in arm 1 and in three children in arm 2; there were no significant differences in adverse events between the two arms. The study did not meet its primary endpoint, but the authors concluded that early aggressive therapy in children with recent-onset polyarticular JIA resulted in clinically inactive disease by 6 months and clinical remission on medication after 1 year of treatment in substantial proportions of children in both arms.

Although once weekly etanercept was used in the above trial, twice weekly etanercept is the approved dose of etanercept for JIA. Horneff et al treated 20 children aged 4-17 years with $0.8 \mathrm{mg} / \mathrm{kg}$ of etanercept weekly in a 3-month open-label trial. ${ }^{18}$ Active polyarticular JIA was defined as five or more swollen, tender, or painful joints combined with limited range of motion. Efficacy was assessed using the American College of Rheumatology (ACR) Pedi30/50/70 criteria, which is similar to the ACR 20/50/70 criteria. ${ }^{19,20}$ At study initiation, the children demonstrated high disease activity. At 4 weeks, a rapid reduction in disease activity was seen with an ACR Pedi30/50/70 response reached by $75 \% / 35 \% / 10 \%$ of the children, at 8 weeks $90 \% / 75 \% / 35 \%$, and at 12 weeks $95 \% / 75 \% / 75 \%$. Thirty-seven adverse events were reported, none were serious, with injection site reactions and minor infections being the most frequent. The children will continue to be followed in the German JIA Registry. Although there was no comparative arm with etanercept $0.4 \mathrm{mg} / \mathrm{kg}$, the response rates suggested that once weekly etanercept provides an excellent therapeutic response.

Otten et al presented data from a prospective ongoing multicenter observational study of patients with JIA treated with etanercept from the Dutch registry that a delayed clinical response can be seen in patients with JIA who have not had a clinical response at 12 weeks. ${ }^{21}$ One hundred seventy-nine children with a median age of 5.8 years were studied at disease onset. Thirty-four of the children did not respond at 12 weeks, but 20 children continued therapy and eleven achieved response in the ensuing weeks. These authors concluded that consideration of continuing therapy for at least 6 months 
should be given for children who have not responded after 12 weeks of etanercept therapy.

Solari et al performed chart reviews of children with JIA who were treated with etanercept between January 2002 and January 2011 with the intent to identify factors that were associated with a response to etanercept; these clinical characteristics associated with achieving inactive disease were determined through univariate analyses and Cox regression procedures. ${ }^{22}$ The charts of 173 children with JIA who were treated with etanercept for a median of 2.2 years (range $0.5-10.5$ years) were reviewed. Eighty-seven children (50.3\%) achieved inactive disease after a median of 5 months of treatment. At last follow-up, 85 children (49.1\%) still had inactive disease and $70(40.5 \%)$ were in clinical remission on medication. The probability of achieving inactive disease after 6,12 , and 24 months was $24 \%, 46 \%$, and $57 \%$, respectively. By Cox regression analysis, achieving inactive disease was associated with lack of wrist involvement and age of onset of JIA at less than 3.6 years.

Most studies of JIA have enrolled a small number of children compared to the studies of adults with rheumatoid arthritis. As a result, much data concerning the efficacy and safety of etanercept has been reported in registries from around the world; a few examples of registry data have been presented above. In 2008, Nielsen et al presented data from the Italian Registry that etanercept may reduce radiographic progression in JIA..$^{23}$ The study cohort was composed of children with JIA who were treated with etanercept between March 1999 (see Table 1 for a summary of efficacy data) and January 2004. The clinical response since the beginning of etanercept therapy was measured by means of the ACR Pedi30/50/70. Radiographic damage was scored using the Poznanski method that was specifically developed for use in children and has been demonstrated to be valid for the assessment of progression of radiographic damage in JIA. ${ }^{23} \mathrm{As}$ of June 2004, 211 children with JIA were treated in 17 centers and enrolled in the Italian etanercept registry. All clinical measures showed a marked improvement ranging from $47 \%$ to $89 \%$. The median change in Poznanski score between baseline and 1 year was +0.3 units, which meant that, on average, children experienced improvement in radiographic progression. The frequency of ACR Pedi30/50/70 responses at 1 year was $77 \% / 72 \% / 50 \%$. In the past, methotrexate was shown to be capable of reducing radiographic progression in JIA; this study did not have a methotrexate-only comparator arm as it was practice to use etanercept in children who had failed methotrexate. ${ }^{24,25}$ Most of the children in the study were taking methotrexate in addition to etanercept; thus, it was not possible to compare the efficacy of etanercept alone versus that of the combination of etanercept and methotrexate.

The German JIA Registry published an open-label, nonrandomized study of children who had previously failed to respond to at least one non-biologic DMARD. ${ }^{26} \mathrm{~A}$ total of 722 children with JIA with data from at least one follow-up visit were identified; 118 children who had been treated with DMARDs were excluded. A total of 504 children were treated with a combination of methotrexate and etanercept and 100 children were treated with etanercept as the control group. At 1 year, 55 children in the etanercept group and 376 children in the combination therapy group were available for comparison. For the intention to treat analysis, 65 children who stopped therapy prematurely were included. All parameters of disease activity improved significantly in both treatment groups. At 1 year, the ACR Pedi30/50/70 was $81 \% / 74 \% / 62 \%$ for the combination therapy group and $70 \% / 63 \% / 45 \%$ for the etanercept monotherapy group. The likelihood of achieving an ACR Pedi70 increased with combination therapy with an odds ratio of 2.1 (95\% confidence interval 1.2-3.5). Twenty-five infections and 23 noninfectious severe adverse events including three malignancies occurred in the combination therapy group and one infection and three non-infectious severe adverse events occurred in the etanercept monotherapy group. A limitation of this study is that there was no methotrexate-only arm for comparison.

The Dutch Registry published a long-term follow-up study of the safety and effectiveness of etanercept in JIA. ${ }^{27}$ The data from this registry demonstrated, in a real-life setting with all Dutch JIA patients being treated with etanercept, an initial and sustained response to etanercept in JIA for up to 75 months. The registry also discusses that the management of JIA is complex and often requires a multidisciplinary approach and that the impact of these musculoskeletal conditions on an individual's life cannot be measured only by clinical measures of disease activity, but that self-reported measures such as pain severity and limitation of daily activity provide important disease assessments as well. The first prospective long-term study of the health-related quality of life changes in JIA patients receiving etanercept treatment over 27 months was performed as part of the registry. At study entry, the children had extremely low health-related quality of life levels which improved greatly, sometimes even to the same level as in healthy children. The authors stated that it was crucial to include health-related quality of life measures to understand the complete impact of etanercept treatment on children with JIA and their families. The cost of etanercept therapy was also investigated. After starting etanercept 
Table I Efficacy data

\begin{tabular}{|c|c|c|c|c|c|}
\hline Citation & Study design & Drug dosage & Age (years) & Sample size & Results \\
\hline Lovell et al ${ }^{10}$ & $\begin{array}{l}\text { 3-month OL, then } \\
\text { 4-month DBPCT }\end{array}$ & ETN $0.4 \mathrm{mg} / \mathrm{kg} 2 \times /$ week & $4-17$ & 69 & $\begin{array}{l}\text { Pedi ACR50/70 } \\
3 \text { months: } 64 \% / 36 \% \text {, } \\
>7 \text { months: } 72 \% / 44 \%\end{array}$ \\
\hline Lovell et al" & OLE $4-8$ years $\mathrm{F} / \mathrm{U}$ & ETN $0.4 \mathrm{mg} / \mathrm{kg} 2 \times /$ week & $4-17$ & 42 & $\begin{array}{l}\text { Pedi ACR30/50/70/90/100 } \\
>8 \text { years: } 78 \%, 62 \%, 47 \%, 31 \%, 18 \%\end{array}$ \\
\hline Schmeling et $\mathrm{al}^{13}$ & OLE 24 weeks & $\begin{array}{l}\text { ETN } 0.4 \mathrm{mg} / \mathrm{kg} 2 \times / \text { week } \\
\text { MTX } 10 \mathrm{mg} / \mathrm{m}^{2} / \text { week }\end{array}$ & $2.5-9$ & 7 & sllA did not respond \\
\hline Kietz et al ${ }^{14}$ & OL 4-26 months & ETN $0.4 \mathrm{mg} / \mathrm{kg} 2 \times /$ week & $5-32$ & 22 & $\begin{array}{l}\text { Decrease } 49 \% \text { in SJC, decrease } \\
94 \% \text { in TJC, decrease } 64 \% \text { in ESR }\end{array}$ \\
\hline Haapasaari et al ${ }^{15}$ & I-year OL & $\begin{array}{l}\text { ETN } 0.4 \mathrm{mg} / \mathrm{kg} 2 \times / \text { week, } \\
\text { MTX } 15-20 \mathrm{mg} / \mathrm{m}^{2} / \text { week }\end{array}$ & $3-15$ & 31 & $\begin{array}{l}\text { Excellent clinical response; outcome } \\
\text { measures: ESR, CRP, number of steroid } \\
\text { injections, inpatient days needed }\end{array}$ \\
\hline Giannini et al ${ }^{17}$ & 3-year OL & $\begin{array}{l}\text { ETN } 0.4 \mathrm{mg} / \mathrm{kg} 2 \times / \text { week } \\
\text { MTX } 10 \mathrm{mg} / \mathrm{m}^{2} / \text { week } \\
\text { ETN+MTX ETN } 0.4 \mathrm{mg} / \mathrm{kg} 2 \times / \\
\text { week plus MTX } 10 \mathrm{mg} / \mathrm{m}^{2} / \text { week }\end{array}$ & $2-18$ & $\begin{array}{l}103 \\
197 \\
294\end{array}$ & $\begin{array}{l}\text { Scores for PGA and AJC improved } \\
\text { from baseline and sustained up to } \\
36 \text { months }\end{array}$ \\
\hline Wallace et $\mathrm{al}^{6}$ & 12 months $\mathrm{DB}, \mathrm{PC}$ & $\begin{array}{l}\text { Arm I: ETN } 0.8 \mathrm{mg} / \mathrm{kg} / \text { week + } \\
\text { prednisolone } 0.5 \mathrm{mg} / \mathrm{kg} / \text { day + } \\
\text { MTX } 0.5 \mathrm{mg} / \mathrm{kg} / \text { week } \\
\text { Arm 2: MTX } 0.5 \mathrm{mg} / \mathrm{kg} / \text { week }\end{array}$ & $2-17$ & 85 & $\begin{array}{l}\text { Did not meet primary endpoint. } \\
\text { Arm I, at } 6 \text { months I7/42 CID (40\%), } \\
\text { Arm } 2 \text { I0/43 CID (23\%) }\end{array}$ \\
\hline Horneff et al ${ }^{18}$ & 3-month OL & ETN $0.8 \mathrm{mg} / \mathrm{kg} /$ week & $4-17$ & 20 & $\begin{array}{l}\text { I2-week ACR Pedi30/50/70 } \\
95 \%, 75 \%, 75 \%\end{array}$ \\
\hline Solari et $\mathrm{a}^{22}$ & Chart review & ETN $0.4 \mathrm{mg} / \mathrm{kg} 2 \times /$ week & & 173 & $\begin{array}{l}87 / 173(50.3 \%) \text { achieved inactive } \\
\text { disease at } 0.6 \text { years. At last } F / U, 85 / 173 \\
(49.1 \%) \text { had inactive } d z \text { and } 70 / 173 \\
(40.5 \%) \text { were in clinical remission }\end{array}$ \\
\hline Nielsen et $\mathrm{a}^{23}$ & Italian registry OL & ETN $0.4 \mathrm{mg} / \mathrm{kg} 2 \times /$ week & $2.2-4.3$ & 40 & $\begin{array}{l}\text { ACR Pedi30/50/70 } \\
\text { at I year: } 77 \%, 72 \%, 50 \%\end{array}$ \\
\hline Horneff et $\mathrm{a}^{26}$ & $\begin{array}{l}\text { OL non- } \\
\text { randomized }\end{array}$ & $\begin{array}{l}\text { ETN } 0.8 \mathrm{mg} / \mathrm{kg} / \text { week + } \\
\text { MTX } 10-15 \mathrm{mg} / \mathrm{m}^{2} / \text { week } \\
\text { versus ETN } 0.8 \mathrm{mg} / \mathrm{kg} / \text { week }\end{array}$ & $2-18$ & 504 & $\begin{array}{l}\text { ACR Pedi20/50/70 } \\
\text { at I month: } 67 \%, 54 \%, 30 \% \\
\text { at } 3 \text { months: } 79 \%, 61 \%, 39 \% \\
\text { at } 6 \text { months: } 82 \%, 70 \%, 50 \%\end{array}$ \\
\hline Prince $^{27}$ & Observational & ETN $0.4 \mathrm{mg} / \mathrm{kg} 2 \times /$ week & $0-18$ & 146 & $\begin{array}{l}>3 \text { months. } 77 \% \text { had ACR Pedi30, } \\
36 \% \text { had ACR Pedil } 00\end{array}$ \\
\hline Bracaglia et $\mathrm{a}^{29}$ & 23-month OL & ETN $0.4 \mathrm{mg} / \mathrm{kg} 2 \times /$ week & $1.5-4$ & 25 & $\begin{array}{l}\text { ACR Pedi30/50/70 } \\
\text { At } 6 \text { months: } 71.4 \%, 62 \%, 43 \% \\
\text { Last F/U: } 80 \%, 72 \%, 64 \%\end{array}$ \\
\hline Anink et $\mathrm{a}^{30}$ & $\begin{array}{l}\text { Registry median } \\
\text { F/U I } 3.7 \text { month }\end{array}$ & $\begin{array}{l}\text { I4 ETN } 0.4 \mathrm{mg} / \mathrm{m}^{2} 2 \times / \text { week } \\
\text { Two ADA } 24 \mathrm{mg} / \mathrm{m}^{2} \text { q } 2 \text { weeks }\end{array}$ & $2.1-13.5$ & 16 & $63 \%$ developed inactive disease \\
\hline Horneff et $\mathrm{a}^{|3|}$ & $\begin{array}{l}\text { OL, two part study } \\
\text { First part } 12 \text { weeks }\end{array}$ & ETN 0.8 mg/kg/week & $2-17$ & $\begin{array}{l}127 \\
60 \text { eoJIA } \\
38 \text { ERA } \\
29 \text { JPSA }\end{array}$ & $\begin{array}{l}\text { ACR Pedi50/70/90 } \\
81.1 \%, 61.5 \%, 29.8 \%\end{array}$ \\
\hline
\end{tabular}

Abbreviations: ACR, American College of Rheumatology; ADA, adalimumab; AJC, acute joint count; CID, clinically inactive disease; CRP, C reactive protein; DB, doubleblind; dz, disease; eoJIA, extended oligoarticular JIA; ERA, early RA; ESR, erythrocyte sedimentation rate; ETN, etanercept; F/U, follow-up; JPSA, juvenile psoriatic arthritis; MTX, methotrexate; DBPCT, double blind placebo controlled trial; OL, open-label; OLE, open label extension; PC, placebo-controlled; Pedi, Pediatric ACR; PGA, physician global assessment; SJC, swollen joint count; sJIA, systemic JIA; TJC, tender joint count; q, per.

therapy, the total direct medical costs tripled, mostly due to the cost of etanercept but other direct medical costs such as cost of consultations and hospitalizations decreased 55\% during the 27 months of etanercept treatment. The authors stated that considering the substantial gain in quality of life in JIA patients who were refractory to conventional therapy and at risk for long-term disability and pain that the costs of etanercept were justifiable. They stated that it was also expected that early effective treatment of JIA can prevent high costs from continuing into adulthood.

Otten et al presented a follow-up to their initial assessment of factors associated with treatment response to etanercept in JIA as part of the Dutch registry. ${ }^{28}$ Fifteen months after initiation of treatment with etanercept in 262 children, 85 (32\%) were considered to be excellent responders, 92 (36\%) intermediate responders, and 85 (32\%) poor responders. Compared 
to an intermediate or poor response, an excellent response was associated with lower baseline disability score, fewer DMARDs being used before starting etanercept, and younger age of disease onset. Compared with an intermediate or excellent response, a poor response was associated with systemic JIA and female sex. During the first 15 months of etanercept therapy, 119 children experienced one or more infectious, noninfectious, or serious adverse events. During this same period of time, 61 children discontinued etanercept therapy.

Bracaglia et al presented data regarding the safety and efficacy of etanercept in a cohort of patients with JIA under 4 years of age. ${ }^{29}$ Data was collected during treatment with etanercept in 25 children who began treatment at a mean age of 3 years (18-48 months) for a mean period of 23 months. All children received concomitant medications: 24 methotrexate, three cyclosporin A, and ten glucocorticoids. After the first 6 months of treatment, 15 (71.4\%) children achieved an ACR Pedi30 response; at the last observation, $20(80 \%)$ had achieved an ACR Pedi30 response. ACR Pedi50 responses were observed in $62 \%$ at 6 months and $72 \%$ at the last observation. ACR Pedi70 responses were seen in $43 \%$ at 6 months and $64 \%$ at the last follow-up. Five children (20\%) stopped etanercept due to lack of efficacy. Two children ( $8 \%$ ) developed adverse events, both primary varicella in children who had not been vaccinated. No cases of cancer, opportunistic infections, or tuberculosis were reported.

Most of data that has been reviewed above addresses the use of etanercept in polyarticular JIA as this is the approved indication in the US and the largest source of safety and

Table 2 Safety data

\begin{tabular}{|c|c|c|c|c|c|}
\hline Citation & Study design & Drug dosage & Age (years) & Sample size & Safety data (events/patient-year) \\
\hline \multirow[t]{2}{*}{ Lovell et a ${ }^{10}$} & 3-month OL, then & \multirow[t]{2}{*}{ ETN $0.4 \mathrm{mg} / \mathrm{kg} 2 \times /$ week } & \multirow[t]{2}{*}{$4-17$} & \multirow[t]{2}{*}{69} & \multirow[t]{2}{*}{ One depression, one Gltis } \\
\hline & 4-month DBPCT & & & & \\
\hline Lovell et al" & OLE 4-8 years F/U & ETN $0.4 \mathrm{mg} / \mathrm{kg} 2 \times /$ week & $4-17$ & 42 & $\begin{array}{l}0.03 \text { medically important infections/ } \\
\text { patient-year }\end{array}$ \\
\hline \multirow[t]{2}{*}{ Schmeling et $\mathrm{al}^{13}$} & \multirow[t]{2}{*}{ OLE 24 weeks } & ETN $0.4 \mathrm{mg} / \mathrm{kg} 2 \times /$ week & \multirow[t]{2}{*}{$2.5-9$} & \multirow[t]{2}{*}{7} & \multirow[t]{2}{*}{ One flare JIA, two ISRs } \\
\hline & & MTX $10 \mathrm{mg} / \mathrm{m}^{2} /$ week & & & \\
\hline Kietz et $\mathrm{al}^{14}$ & OL 4-26 months & ETN $0.4 \mathrm{mg} / \mathrm{kg} 2 \times /$ week & $5-32$ & 22 & No infections, minor ISRs \\
\hline \multirow[t]{2}{*}{ Haapasaari et al ${ }^{15}$} & \multirow[t]{2}{*}{ I-year OL } & ETN 0.4 mg/kg 2x/week, & \multirow[t]{2}{*}{$3-15$} & \multirow[t]{2}{*}{31} & \multirow[t]{2}{*}{ Not reported } \\
\hline & & MTX I5-20 mg/m²/week & & & \\
\hline \multirow[t]{4}{*}{ Giannini et al ${ }^{17}$} & \multirow[t]{4}{*}{ 3-year OL } & ETN 0.4 mg/kg 2×/week & \multirow[t]{4}{*}{$2-18$} & 103 & \multirow[t]{4}{*}{ ETN 0.187, ETN + MTX 0.216} \\
\hline & & MTX $10 \mathrm{mg} / \mathrm{m}^{2} /$ week & & 197 & \\
\hline & & ETN+MTX ETN 0.4 mg/kg 2x/ & & 294 & \\
\hline & & week + MTX 10 mg $/ \mathrm{m}^{2} /$ week & & & \\
\hline \multirow[t]{4}{*}{ Wallace et al ${ }^{6}$} & \multirow[t]{4}{*}{12 months $\mathrm{DB}, \mathrm{PC}$} & Arm I: ETN 0.8 mg/kg/week + & \multirow[t]{4}{*}{$2-17$} & \multirow[t]{4}{*}{85} & \multirow{4}{*}{$\begin{array}{l}\text { Arm I: one abscess, one elevated LFT, } \\
\text { OL: one pneumonia, one steroid } \\
\text { psychosis }\end{array}$} \\
\hline & & prednisolone 0.5 mg/kg/day + & & & \\
\hline & & MTX 0.5 mg/kg/week & & & \\
\hline & & Arm 2: MTX 0.5 mg/kg/week & & & \\
\hline Horneff et $\mathrm{al}^{18}$ & 3-month OL & ETN 0.8 mg/kg/week & $4-17$ & 20 & $\begin{array}{l}\text { No SAEs, } 37 \text { AEs including one ISR, } \\
\text { one minor infection }\end{array}$ \\
\hline Solari et a ${ }^{22}$ & Chart review & ETN $0.4 \mathrm{mg} / \mathrm{kg} 2 \times /$ week & & 173 & Not reported \\
\hline Nielsen et $\mathrm{a}^{23}$ & Italian Registry OL & ETN $0.4 \mathrm{mg} / \mathrm{kg} 2 \times /$ week & $2.2-4.3$ & 40 & Not reported \\
\hline \multirow[t]{4}{*}{ Horneff et $\mathrm{al}^{26}$} & \multirow{4}{*}{$\begin{array}{l}\text { OL non- } \\
\text { randomized }\end{array}$} & ETN $0.8 \mathrm{mg} / \mathrm{kg} /$ week + MTX & \multirow[t]{4}{*}{$2-18$} & \multirow[t]{4}{*}{504} & ETN + MTX: 25 infectious SAEs, \\
\hline & & $10-15 \mathrm{mg} / \mathrm{m}^{2} /$ week versus & & & 23 non-infectious SAEs including three \\
\hline & & ETN 0.8 mg/kg/week & & & malignancies. ETN: one infectious SAE \\
\hline & & & & & and three non-infectious SAEs \\
\hline Prince $^{27}$ & Observational & ETN $0.4 \mathrm{mg} / \mathrm{kg} 2 \times /$ week & $0-18$ & 146 & Two sarcoidosis, 0.515 \\
\hline Bracaglia et $\mathrm{al}^{29}$ & 23-month OL & ETN $0.4 \mathrm{mg} / \mathrm{kg} 2 \times /$ week & $1.5-4$ & 25 & Two Zoster, two IBD \\
\hline \multirow[t]{3}{*}{ Anink et a ${ }^{10}$} & Registry median & I4 ETN $0.4 \mathrm{mg} / \mathrm{m}^{2}$ 2×/week & $2.1-13.5$ & 16 & Two on ETN: one ruptured appendix, \\
\hline & F/U I 3.7 months & Two ADA $24 \mathrm{mg} / \mathrm{m}^{2}$ q 2 weeks & & & one restricted pulmonary function \\
\hline & & & & & None on ADA \\
\hline Horneff et $\mathrm{al}^{31}$ & OL, two part study & ETN $0.8 \mathrm{mg} / \mathrm{kg} /$ week & $2-17$ & $127=$ & Non-infectious AEs occurred in \\
\hline & First part 12 weeks & & & 60 eoJlA, & 45 patients (35.4\%). No difference in \\
\hline & & & & 38 ERA, & rates of non-infectious or infectious AEs \\
\hline & & & & 29 JPSA & between the three subgroups. Infections \\
\hline & & & & & reported in 58 patients (45.7\%) \\
\hline
\end{tabular}

Abbreviations: ADA, adalimumab; AE, adverse event; DB, double-blind; eojIA, extended oligoarticular JIA; ERA, early RA; ETN, etanercept; F/U, follow-up; Gltis, gastroenteritis; IBD, inflammatory bowel disease; ISR, injection site reaction; JIA, juvenile idiopathic arthritis; JPSA, juvenile psoriatic arthritis; LFTs, liver function tests; MTX, methotrexate; DBPCT, double blind placebo controlled trial; OL, open-label; OLE, open label extension; PC, placebo-controlled; SAE, serious adverse event; q, per. 
efficacy data. Anink et al selected children from the Dutch Registry who had been diagnosed with oligoarticular JIA..$^{30}$ As of February 2011, only 16 children with oligoarticular JIA were identified. The median age of onset was 8.4 years (range 2.1-13.5 years), 56.3\% were antinuclear-antibodypositive, and $18.8 \%$ had a history of uveitis. All of the children had been treated with methotrexate and $81.3 \%$ were treated with intra-articular glucocorticoids. Fourteen children were treated with etanercept and two children who had uveitis in addition to arthritis were started on adalimumab. These children had few affected joints (median of two active joints), but the patient/parent assessments of pain were high with a visual analog score (VAS) of 51 (on a scale of 0-100) and the well-being VAS was 44; the physician evaluation of the disease activity was moderately high with a VAS of 36. After 3 months of anti-TNF therapy, $63 \%$ of the children had achieved inactive disease and after 15 months nine out of ten children had achieved inactive disease. Anti-TNF therapy was well-tolerated in this small cohort. This registry also reported the results of eight children with psoriatic JIA and their response to etanercept was similar to that of children with polyarticular JIA.

Data regarding the use of etanercept in the treatment of juvenile spondyloarthropathy are available from one openlabel Phase IIIb study, other open-label studies, registries, retrospective studies, and case reports. The largest study is the CLIPPER study, which is an ongoing Phase IIIB, open-label, prospective, multicenter, two-part study that evaluates the efficacy and safety of etanercept in 127 children with extended oligoarticular JIA ( $n=60$, ages $2-17$ years), enthesitis-related arthritis ( $n=38$, ages $12-17$ years), or juvenile psoriatic arthritis ( $n=29$, ages $12-17$ years). In part one of the study, each child received etanercept $0.8 \mathrm{mg} / \mathrm{kg}$ subcutaneously once weekly with a maximum dose of $50 \mathrm{mg} /$ week for 12 weeks. ${ }^{31}$ Concomitant therapy with one DMARD, oral glucocorticoid at a dose of $10 \mathrm{mg} /$ day or less and one NSAID were allowed. The primary endpoint is the proportion of children achieving an ACR Pedi30 at week 12. A total of 122 children completed the 12 -week study. At week 12, 88.6\% of the children achieved an ACR Pedi30 response. An ACR Pedi30 response was achieved by $89.7 \%$ of children with extended oligoarticular JIA, $83 \%$ of children with enthesitis-related arthritis, and $93.1 \%$ of children with psoriatic JIA. The overall ACR Pedi50/70/90 response rates at week 12 were $81.1 \%, 61.5 \%$, and $29.8 \%$, respectively. Overall, inactive disease was achieved by $12.1 \%$ of the children, and by $11.9 \%, 16.7 \%$, and $6.9 \%$ of children with extended oligoarticular JIA, enthesitis-related arthritis, and psoriatic JIA, respectively.
This degree of efficacy may not be generalizable to all subtypes of JIA. Lovell et al showed that children with systemic JIA treated with etanercept had a higher rate of disease flare $(44 \%)$ compared to other disease subsets. ${ }^{10}$ Children with systemic JIA enrolled in the Dutch Registry treated with etanercept had lower ACR Pedi30/50/70 responses $(P<0.01)$ than those with other subtypes, and withdrawal due to lack of efficacy was also greater $(P<0.001)$. Of interest, those children with systemic JIA who did respond demonstrated a similar efficacy compared to other subtypes, in the longterm, with $38 \%$ of the children with systemic JIA attaining remission on etanercept. ${ }^{27}$

Due to the high cost of etanercept and unknown longterm safety, Pratsidou-Gertsi et al presented data of eleven children with JIA who discontinued etanercept due to disease remission. ${ }^{32}$ All eleven patients flared during the follow-up period of 12.25-27 months after etanercept withdrawal. The median remission after etanercept withdrawal was 3 months. The flares were treated and controlled with methotrexate, methotrexate plus cyclosporine A in ten children, and methotrexate plus a TNF-inhibitor in one child.

Postepski et al also evaluated clinical remission in JIA after termination of etanercept therapy. ${ }^{33}$ They retrospectively analyzed data of 39 children with JIA from two clinical pediatric rheumatology centers in Poland, all of whom stopped etanercept therapy as they achieved inactive disease. Etanercept therapy was initiated after a mean of 33.7 months of disease and the mean duration of therapy with etanercept was 34.7 months with a mean duration of remission on medication of 21.3 months. The mean duration of remission after etanercept was stopped was 14.2 months. Twelve children (30.8\%) did not develop a disease exacerbation until the end of the study. Flares less than 6 months after discontinuing etanercept were seen in 15 children (38.5\%). Twelve children $(30.8 \%)$ restarted etanercept after disease exacerbation and all of them responded satisfactorily. This study confirms data from other studies that discontinuation of etanercept usually results in exacerbation of disease.

Lamot et al assessed the long term efficacy and tolerability of etanercept and infliximab in children with JIA. ${ }^{34}$ This was a retrospective, observational study of 41 children treated with anti-TNF therapy. Six months after initiating anti-TNF therapy, 35 children achieved an ACR Pedi20 (92.1\%), 33 children achieved an ACR Pedi30 (86.8\%), 31 children achieved an ACR Pedi50 (81.6\%), 28 children achieved an ACR Pedi70 (73.7\%), and 20 children achieved an ACR Pedi90 (52.6\%). Eleven children had a flare in the study period (28.9\%): three on infliximab $(7.9 \%)$, five on 
etanercept (13.1\%), and three on both medications as children were allowed to switch from one biologic therapy to another $(7.9 \%)$. At 1 year, 15 children met the criteria for clinical remission on medications; eight on etanercept and seven on infliximab. Eleven children met the criteria for clinical remission off medications: seven were taking infliximab, three were taking etanercept, and one was switched from etanercept to infliximab. There was no significant difference in the duration, response, flare, resistance, or adverse events between both therapies; long remissions were rare.

\section{Safety and tolerability of etanercept}

As TNF plays a critical role in inflammation and immunity, there is a concern that therapeutic inhibition of TNF with a TNF-antagonist such as etanercept may potentially lead to immune suppression, resulting in increased risk of infections and malignancies. In the study by Lovell et al, there was no significant difference between the rates of adverse events in the etanercept-treated group versus the placebo-exposed group. ${ }^{10}$ In the open-label study, the most common adverse events were injection site reactions (39\%), upper respiratory tract infections $(35 \%)$, headache $(20 \%)$, rhinitis $(16 \%)$, abdominal pain (16\%), vomiting (14\%), pharyngitis (14\%), rash $(10 \%)$, gastrointestinal infection $(12 \%)$, and nausea (12\%). The overall infection rate was $22.8 \%$ with 32 minor infections and two serious infections: bacterial pneumonia and a prosthetic hip infection. In the 8-year open-label extension trial of etanercept, Lovell et al collected 318 patient-years of exposure to etanercept. ${ }^{11}$ In the original randomized controlled trial, severe adverse events occurred in $23 \%$ of the original cohort, representing 0.12 serious adverse events per patientyear. In the extension trial, there was no increase in the rate of serious adverse events; $7 \%$ of the children discontinued etanercept therapy due to adverse events. There were nine cases of "medically important infections" including pyelonephritis, peritonitis, appendicitis, aseptic meningitis due to varicella, acute varicella infection, soft tissue infection, sepsis requiring foot amputation, gastrointestinal infection, dental abscess, and postoperative wound infection. There were no cases of systemic lupus erythematosus, tuberculosis, opportunistic infections, demyelination, malignancy, or death. ${ }^{11}$ Injection site reactions were common (28\%), but did not usually result in termination of the study drug. There was no increase in the rate of medically important infections with time.

Kilic et al retrospectively reviewed the cases of 144 children in the Turkish database; they were evaluated every 6 months for tuberculosis. ${ }^{35}$ Children included in the study had: JIA $(n=132)$, enthesitis-related arthritis $(n=14)$, juvenile psoriatic arthritis $(n=4)$, chronic idiopathic uveitis $(n=4)$, and chronic arthritis related to familial Mediterranean fever $(n=8)$. Mean age was 12.25 years (4.08-19.41 years), mean duration of JIA was 5.86 years $(0.66-15$ years), and the mean duration of anti-TNF therapy was 2.41 years $(0.6-7$ years). Anti-TNF therapies included etanercept $(n=133)$, infliximab $(n=30)$, and adalimumab $(n=6)$. Children could be switched from one TNF inhibitor to another if their disease was unresponsive to their current therapy. During the follow-up period, seven children $(4.8 \%)$ with a positive tuberculin skin test were treated with isoniazid prophylaxis. No children treated with etanercept developed tuberculosis; one child on infliximab for 2 years with secondary uveitis developed a positive QuantiFERON gold test while on isoniazid prophylaxis and was started on anti-tuberculosis drug therapy. The authors recommended evaluation every 6 months for tuberculosis of children with JIA treated with anti-TNF therapy in Turkey. None of the children studied in the Dutch registry developed tuberculosis during etanercept therapy. Two children developed sarcoidosis. ${ }^{27}$

The role of TNF in human cancer biology is not clear but it has been hypothesized that TNF inhibition may increase the risk of malignancy, particularly with prolonged, continuous exposure to TNF blockade. ${ }^{36}$ Both the published background rates of malignancy in children with JIA, as well as the rates in those treated with anti-TNF agents, have varied considerably. Data from the Swedish registry reported a 4.2-fold increased risk of lymphoproliferative malignancy since 1987 and a 2.3-fold increased risk in overall malignancies in children with JIA who had not been treated with anti-TNF therapy. ${ }^{37}$ Results from a US commercial claims database demonstrated a four-fold increased risk of malignancy in children with JIA compared to the general pediatric population. ${ }^{38} \mathrm{On}$ the other hand, data from three different Canadian registries demonstrated no increased risk of malignancy in children with JIA. ${ }^{39}$ Based on these concerns, the US Food and Drug Administration in 2009 required boxed warnings on the labels for the TNF-inhibitor therapies that warned patients that lymphoma and other malignancies, some fatal, have been reported in children and adolescents treated with TNF blocker therapy. In 2011, the US Food and Drug Administration mandated that the pharmaceutical industry sponsors of TNF-blocker studies initiate a 10-year postmarketing commitment to expedite reporting of all global cases of malignancies in children and young adults treated with TNF-inhibitor therapy and to annually report this data. ${ }^{40}$

Hooper et al presented data concerning the malignancies that were reported in patients exposed to etanercept aged 
30 years or younger from the Amgen clinical trial database in addition to postmarketing global safety databases (PMD). ${ }^{40}$ Two malignancies were reported in the clinical trial database: one in the etanercept treated group and one in the placebo group. Postmarketing etanercept exposure was 231,404 patient-years $(62,379$ patient-years in children 0-17 years; 168,485 patient-years in patients $18-30$ years). Reporting rates of malignancy per 100,000 patient-years in the PMD was 32.0 and in the Surveillance Epidemiology and End Results (SEER) database 15.9; of note the SEER database is comprised of the general US population so this data is not comparing children with JIA treated with etanercept versus children with JIA who are TNF-naïve. This is important, as discussed above, as children with active JIA may have an increased risk of malignancy due to this chronic inflammatory state. Five or more cases of leukemia, lymphoma, melanoma, thyroid cancer, and cervical cancer were reported; the incidence of all of these malignancies was similar between the PMD and SEER databases except for the incidence of Hodgkin's lymphoma. PMD reporting rates per 100,000 patient-years and SEER incidence rates for Hodgkin lymphoma in the $0-17$ year age group were 9.54 and 0.9 , respectively. These data suggest that a relationship between etanercept therapy and the development of solid tumors does not exist; whether a causal relationship exists between etanercept therapy and Hodgkin's lymphoma is unknown.

Constatin et al reported the safety and efficacy of etanercept in extended oligoarticular arthritis, enthesitis-related arthritis, and psoriatic JIA over 96 weeks. ${ }^{41}$ The most frequently reported non-infectious adverse events were headache (5.5\%), abdominal pain (3.1\%), diarrhea (3.1\%), fatigue $(3.1 \%)$, and pyrexia (3.1\%). There were no differences in the rates of non-infectious or infectious adverse events between the three subgroups of JIA. The most commonly reported treatment-related infections were upper respiratory tract infection (65\%), pharyngitis (39\%), gastroenteritis (17\%), bronchitis (14.8\%), and rhinitis (13.4\%). No cases of malignancy, tuberculosis, demyelinating disorders, or deaths were reported.

Many case reports have been published of rare adverse reactions to etanercept including one case of thymic enlargement, one case of Crohn's disease, four cases of musculoskeletal infections, six children with uveitis, three cases of scleritis, five cases of psoriasis, one case of subacute thyroiditis, one case of encephalopathy, two cases of anaphylaxis, one case of myelopathy, Blau syndrome, two reported cases of systemic lupus, and five cases of inflammatory bowel disease. ${ }^{42-54}$ The latter study ${ }^{54}$ reported a much higher frequency of neuropsychiatric adverse events of $28.1 \%$ including headaches, anxiety, aggression, fatigue, vertigo, depression, and pain amplification syndromes. Aggression, pain amplification, and severe headache only were reported in children treated with doses of etanercept higher than $0.4 \mathrm{mg} / \mathrm{kg}$ and resolved when the dose was decreased. These data are derived from case reports and open-label trials and therefore cannot provide information on the incidence of these conditions in etanercept-treated compared to controltreated children with JIA.

\section{Patient-focused perspective}

As JIA is associated with impaired growth and development depending on the severity of the chronic inflammation, disease duration, and greater functional involvement, it is important to evaluate the effect of etanercept on these factors. Giannini et al conducted a 3-year, open-label, nonrandomized study of 594 children with polyarticular or systemic JIA treated with etanercept only, etanercept plus methotrexate, or methotrexate alone. Weight, height and body mass index were assessed at baseline and at years 1,2 and $3 .^{55}$ Statistically significant increases in the mean height percentiles from baseline were seen in the children treated with etanercept at year 3 (4.8 percentile points) and in children treated with the combination therapy of etanercept plus methotrexate at years 1,2 , and $3(2.4,3.3$, and 5.6 percentile points, respectively). Statistically significant increases from baseline in the mean weight percentiles were seen at years 1,2 , and 3 in the etanercept group (7.4, 10.0, and 13.0 percentile points, respectively) and the combination therapy of etanercept and methotrexate group $(2.9,6.9$, and 8.4 percentile points, respectively). Statistically significant increases from baseline in the mean BMI percentiles were seen in the etanercept group (range 9.6-13.8 percentile points) and the combination therapy of etanercept and methotrexate group (2.1-5.2 percentile points). In the methotrexate group, the mean height, weight, and body mass percentiles did not change significantly.

Data from Billiau et al show results consistent with those of Giannini et al. ${ }^{56}$ Billiau et al studied 16 children with methotrexate-resistant polyarticular JIA who were given add-on etanercept; the control group was composed of eight children recently diagnosed with polyarticular JIA who were treated with methotrexate. Baseline patient and disease characteristics were similar between the two groups. The children were evaluated at baseline and at 1, 6, 12, and 18 months with respect to linear growth, bone mineral density, disease activity, and body composition. Growth velocity increased significantly in the etanercept plus methotrexate 
group allowing catch-up growth but not in the methotrexate group. A significant increase was also seen in the bone mineral content and lean: fat mass ratio in the etanercept plus methotrexate group but not in the methotrexate group. Bone mineral density as measured by lumbar spine Z-score improved significantly in both groups.

Burnett et al performed a "discrete choice experiment" to examine parents' preferences for drug treatments and health outcomes in JIA and identify health-related and demographic factors that significantly affect choice. ${ }^{57}$ Attributes evaluated included "days missed from school," side effects, "participation in daily activities," "drug treatment," "cost to you," and "child reported pain from arthritis." As expected, parents made tradeoffs between health outcomes and characteristics of the drug treatments. "Participation in daily activities" was the most important attribute, followed by "child reported pain from arthritis" and "cost to you." Parents of older children had stronger preferences for improved control of pain, whereas parents of children with longer disease durations had stronger preferences for improved "participation in daily activities." The parents of children with JIA demonstrated strong preferences for therapies that reduced pain and improved daily functioning in spite of the associated adverse reactions, days missed from school, and level of responsibility required for the administration of the drug. Parents of children with longer disease duration and those who had been prescribed "aggressive therapies" had a greater preference for effective treatment. These findings support the practice of considering parental preferences in making treatment decisions for children with JIA.

\section{Conclusion}

Juvenile idiopathic arthritis is a group of heterogeneous diseases characterized by arthritis of unknown origin with an onset before the age of 16 years. Studies over the last 15 years have led to significant progress in disease classification and new therapies, but presently we are not able to predict which child will respond to a certain therapy. New approaches are necessary to develop reliable, validated biomarkers that can be used to improve and advance the care of children with JIA. Until these biomarkers exist, the treatment of children with JIA is based on the disease subtype, the duration and severity of the disease, and patient/parent/doctor preferences, taking into consideration the benefits and risks of the therapy in addition to cost. Most guidelines suggest that etanercept be used in children with JIA who have failed NSAIDs, oral and/or intra-articular glucocorticoids, and methotrexate.
While some children with JIA are currently being treated with etanercept monotherapy after methotrexate failure, the data from the TREAT trial suggest that combination therapy may be more effective in certain children with polyarticular JIA. More long-term safety data is needed for children with JIA who are treated with this combination and for children with JIA who are diagnosed at a very early age who may be exposed to biologic therapy for many years. Despite these limitations, at present, treatment with etanercept has been shown to significantly improve the quality of life of children with JIA and has an acceptable safety profile.

\section{Disclosure}

Dr Dore receives support for clinical trials, is a consultant and a member of the speakers' bureau for Amgen, Inc., the manufacturers of etanercept. She did not receive any assistance or support in writing this manuscript. The author reports no other conflicts of interest in this work.

\section{References}

1. Peterson LS, Mason T, Nelson AM, O'Fallon WM, Gabriel SE. Juvenile rheumatoid arthritis in Rochester, Minnesota 1960-1993. Is the epidemiology changing? Arthritis Rheum. 1996;39(8):1385-1390.

2. Petty RE, Southwood TR, Manners P, et al. International League of Associations for Rheumatology. International League of Associations for Rheumatology classification of juvenile idiopathic arthritis: second revision, Edmonton, 2001. J Rheumatol. 2004;31(2):390-392.

3. Beukelman T, Patkar NM, Saag KG, et al. 2011 American College of Rheumatology recommendations for the treatment of juvenile idiopathic arthritis: initiation and safety monitoring of therapeutic agents for the treatment of arthritis and systemic features. Arthritis Care Res (Hoboken). 2011;63(4):465-482.

4. Ringold S, Weiss PF, Beukelman T, et al. 2013 update of the 2011 American College of Rheumatology recommendations for the treatment of juvenile idiopathic arthritis: recommendations for the medical therapy of children with systemic juvenile idiopathic arthritis and tuberculosis screening among children receiving biologic medications. Arthritis Rheum. 2013;65(10):2499-2512.

5. Kemper AR, Van Mater HA, Coeytaux RR, Williams JW Jr, Sanders GD. Systematic review of disease-modifying antirheumatic drugs for juvenile idiopathic arthritis. BMC Pediatr. 2012;12:29.

6. Wallace CA, Giannini EH, Spalding SJ, et al. Childhood Arthritis and Rheumatology Research Alliance. Trial of early aggressive therapy in polyarticular juvenile idiopathic arthritis. Arthritis Rheum. 2012;64(6): 2012-2021.

7. Kutukculer N, Caglayan S, Aydogdu F. Study of pro-inflammatory (TNF-alpha, IL-1alpha, IL-6) and T-cell-derived (IL-2, IL-4) cytokines in plasma and synovial fluid of patients with juvenile chronic arthritis: correlations with clinical and laboratory parameters. Clin Rheumatol. 1998;17(4):288-292.

8. Mangge H, Kenzian H, Gallistl S, et al. Serum cytokines in juvenile rheumatoid arthritis. Correlation with conventional inflammation parameters and clinical subtypes. Arthritis Rheum. 1995;38(2):211-220.

9. Enbrel $^{\circledR}$ (etanercept) [prescribing information]. Thousand Oaks: Amgen Inc.; 1998.

10. Lovell DJ, Giannini EH, Reiff A, et al. Etanercept in children with polyarticular juvenile rheumatoid arthritis. Pediatric Rheumatology Collaborative Study Group. N Engl J Med. 2000;342(11): 763-769. 
11. Lovell DJ, Reiff A, Howite NT, et al. Pediatric Rheumatology Collaborative Study Group. Safety and efficacy of up to eight years of continuous etanercept therapy in patients with juvenile rheumatoid arthritis. Arthritis Rheum. 2008;58(5):1496-1504.

12. National Institute for Clinical Excellence. Guidance on the Use of Etanercept for the Treatment of Juvenile Idiopathic Arthritis. Technology Appraisal Guidance - No 35. London: National Institute for Clinical Excellence; 2002. Available from: http://www.nice.org.uk/nicemedia/ live/11446/32321/32321.pdf. Accessed January 18, 2014.

13. Schmeling H, Mathony K, John V, Keysser G, Burdach S, Horneff G. A combination of etanercept and methotrexate for the treatment of refractory juvenile idiopathic arthritis: a pilot study. Ann Rheum Dis. 2001;60(4):410-412.

14. Kietz DA, Pepmueller PH, Moore TL. Therapeutic use of etanercept in polyarticular course juvenile idiopathic arthritis over a two year period. Ann Rheum Dis. 2002;61(2):171-173.

15. Haapasaari J, Kautiainen H, Hannula S, Pohjankoski H, Hakala M. Good results from combining etanercept to prevailing DMARD therapy in refractory juvenile idiopathic arthritis. Clin Exp Rheumatol. 2002;20(6):867-870

16. Ilowite NT. Current treatment of juvenile rheumatoid arthritis. Pediatrics. 2002;109(1):109-115.

17. Giannini EH, Ilowite NT, Lovell DJ, et al. Pediatric Rheumatology Collaborative Study Group. Long-term safety and effectiveness of etanercept in children with selected categories of juvenile idiopathic arthritis. Arthritis Rheum. 2009;60(9):2794-2804.

18. Horneff G, Ebert A, Fitter S, et al. Safety and efficacy of once weekly etanercept $0.8 \mathrm{mg} / \mathrm{kg}$ in a multicentre 12 week trial in active polyarticular course juvenile idiopathic arthritis. Rheumatology (Oxford). 2009;48(8):916-919.

19. Giannini EH, Ruperto N, Ravelli A, Lovell DJ, Felson DT, Martini A. Preliminary definition of improvement in juvenile arthritis. Arthritis Rheum. 1997;40(7):1202-1209.

20. Arnett FC, Edworthy SM, Bloch DA, et al. The American Rheumatism Association 1987 revised criteria for the classification of rheumatoid arthritis. Arthritis Rheum. 1988;31(3):315-324.

21. Otten MH, Prince FH, Twilt M, et al. Delayed clinical response in patients with juvenile idiopathic arthritis treated with etanercept J Rheumatol. 2010;37(3):665-667.

22. Solari N, Palmisani E, Consolaro A, et al. Factors associated with achievement of inactive disease in children with juvenile idiopathic arthritis treated with etanercept. $J$ Rheumatol. 2013;40(2): 192-200.

23. Nielsen S, Ruperto N, Gerloni V, et al. Italian Pediatric Rheumatology Study Group. Preliminary evidence that etanercept may reduce radiographic progression in juvenile idiopathic arthritis. Clin Exp Rheumatol. 2008;26(4):688-692.

24. Harel L, Wagner-Weiner L, Poznanski AK, Spencer CH, Ekwo E, Magilavy DB. Effects of methotrexate on radiologic progression in juvenile rheumatoid arthritis. Arthritis Rheum. 1993;36(10):1370-1374.

25. Ravelli A, Viola S, Ramenghi B, Beluffi G, Zonta LA, Martini A. Radiologic progression in patients with juvenile chronic arthritis treated with methotrexate. J Pediatr. 1998;133(2):262-265.

26. Horneff G, De Bock F, Foeldvari I, et al. German and Austrian Paediatric Rheumatology Collaborative Study Group. Safety and efficacy of combination of etanercept and methotrexate compared to treatment with etanercept only in patients with juvenile idiopathic arthritis (JIA): preliminary data from the German JIA Registry. Ann Rheum Dis. 2009;68(4):519-525.

27. Prince FH. Etanercept in Juvenile Idiopathic Arthritis: Results from the Dutch National ABC-register. Eur J Epidemiol. 2009;6:115-132.

28. Otten MH, Prince FH, Armbrust W, et al. Factors associated with treatment response to etanercept in juvenile idiopathic arthritis. JAMA. 2011;306(21):2340-2347.

29. Bracaglia C, Buonuomo PS, Tozzi AE, et al. Safety and efficacy of etanercept in a cohort of patients with juvenile idiopathic arthritis under 4 years of age. $J$ Rheumatol. 2012;39(6);1287-1290.
30. Anink J, Otten MH, Prince FH, et al. Tumour necrosis factor-blocking agents in persistent oligoarticular juvenile idiopathic arthritis: results from the Dutch Arthritis and Biologicals in Children Register. Rheumatology (Oxford). 2013;52(4):712-717.

31. Horneff G, Burgos-Vargas R, Constantin T, et al. Efficacy and safety of open-label etanercept on extended oligoarticular juvenile idiopathic arthritis, enthesitis-related arthritis and psoriatic arthritis: part 1 (week 12) of the CLIPPER study. Ann Rheum Dis. Epub May 21, 2013.

32. Pratsidou-Gertsi P, Trachana M, Pardalos G, Kanakoudi-Tsakalidou F. A follow-up study of patients with juvenile idiopathic arthritis who discontinued etanercept due to disease remission. Clin Exp Rheumatol. 2010;28(6):919-922.

33. Postępski J, Kobusińska K, Olesińska E, Osińska V, Opoka-Winiarska V. Clinical remission in juvenile idiopathic arthritis after termination of etanercept. Rheumatol Int. 2013;33(10):2657-2660.

34. Lamot L, Bukovac LT, Vidovic M, Frleta M, Harjacek M. The 'headto-head' comparison of etanercept and infliximab in treating children with juvenile idiopathic arthritis. Clin Exp Rheumatol. 2011;29(1): 131-139.

35. Kilic O, Kasapcopur O, Camcioglu Y, Cokugras H, Arisoy N, Akcakaya N. Is it safe to use anti-TNF- $\alpha$ agents for tuberculosis in children suffering with chronic rheumatic disease? Rheumatol Int. 2012;32(9):2675-2679.

36. Calzascia T, Pellegrini M, Hall H, et al. TNF-alpha is critical for antitumor but not antiviral $\mathrm{T}$ cell immunity in mice. $J$ Clin Invest. 2007;117(12):3833-3845.

37. Simard JF, Neovius M, Hagelberg S, Askling J. Juvenile idiopathic arthritis and risk of cancer: a nationwide cohort study. Arthritis Rheum. 2010;62(12):3776-3782.

38. Nordstrom BL, Mines D, Gu Y, Mercaldi C, Aquino P, Harrison MJ. Risk of malignancy in children with juvenile idiopathic arthritis not treated with biologic agents. Arthritis Care Res (Hoboken). 2012;64(9): $1357-1364$

39. Bernatsky S, Rosenberg AM, Oen KG, et al. Malignancies in juvenile idiopathic arthritis: a preliminary report. $J$ Rheumatol. 2011;38(4): 760-763.

40. Hooper M, Wenkert D, Bitman B, Dias VC, Bartley Y. Malignancies in children and young adults on etanercept: summary of cases from clinical trials and post marketing reports. Pediatr Rheumatol Online J. 2013;11(1):35.

41. Constatin T, Foeldvari I, Vojinovic J, et al. Long Term Safety and Efficacy of Etanercept in Pediatric Subjects with Extended Oligoarthcular Juvenile Idiopathic Arthritis, Enthesitis-Related Arthritis or Psoriatic Arthritis. In: Programs and abstracts of the 2013 Annual Meeting of the American College of Rheumatology/Association of Rheumatology Health Professionals; October 25-30, 2013; San Diego, CA. Abstract 280.

42. Sari I, Binicier O, Birlik M, et al. Thymic enlargement in a patient with juvenile idiopathic arthritis during etanercept therapy. Rheumatol Int. 2009;29(5):591-593.

43. Wiegering V, Morbach H, Dick A, Girschick HJ. Crohn's disease during etanercept therapy in juvenile idiopathic arthritis: a case report and review of the literature. Rheumatol Int. 2010;30(6):801-804.

44. Morishita K, Petty R, Cairns R, Bolaria R, Cabral D, Turvey S. Serious musculoskeletal infections in children receiving anti-tumor necrosis factor-alpha therapy: a case series. Clin Rheumatol. 2010;29(6): 677-681.

45. Kakkassery V, Mergler S, Pleyer U. Anti-TNF-alpha treatment: a possible promoter in endogenous uveitis? observational report on six patients: occurrence of uveitis following etanercept treatment. Curr Eye Res. 2010;35(8):751-756.

46. Gaujoux-Viala C, Giampietro C, Gaujoux T, et al. Scleritis: a paradoxical effect of etanercept? Etanercept-associated inflammatory eye disease. J Rheumatol. 2012;39(2):233-239.

47. Perman MJ, Lovell DJ, Denson LA, Farrell MK, Lucky AW. Five cases of anti-tumor necrosis factor alpha-induced psoriasis presenting with severe scalp involvement in children. Pediatr Dermatol. 2012;29(4):454-459. 
48. Yasuji I. Subacute thyroiditis in a patient with juvenile idiopathic arthritis undergoing etanercept treatment: a case report and review of the literature. Mod Rheumatol. 2013;23(2):397-400.

49. Ekici B, Aydın K, Cantez S, ErgülY, Tatlı B. Etanercept-induced encephalopathy in a 7-year-old child. Pediatr Neurol. 2011;45(4):271-273.

50. Crayne CB, Gerhold K, Cron RQ. Anaphylaxis to etanercept in two children with juvenile idiopathic arthritis. J Clin Rheumatol. 2013;19(3): 129-131.

51. Caracseghi F, Izquierdo-Blasco J, Sanchez-Montanez A, MelandoPerez S, Roig-Quilis M, Modesto C. Etanercept-Induced Myelopathy in a Pediatric Case of Blau Syndrome. Case Rep Rheumatol. 2011; 2011:1-5.

52. Bout-Tabaku S, Rivas-Chacon R, Restrepo R. Systemic lupus erythematosus in a patient treated with etanercept for polyarticular juvenile rheumatoid arthritis. J Rheumatol. 2007;34(12):2503-2504.

53. Lepore L, Marchetti F, Facchini S, Leone V, Ventura A. Drug-induced systemic lupus erythematosus associated with etanercept therapy in a child with juvenile idiopathic arthritis. Clin Exp Rheumatol. 2003;21(2):276-277.
54. Gerloni V, Pontikaki I, Gattinara M, Fantini F. Focus on adverse events of tumour necrosis factor alpha blockade in juvenile idiopathic arthritis in an open monocentric long-term prospective study of 163 patients. Ann Rheum Dis. 2008;67(8):1145-1152.

55. Giannini EH, Ilowite NT, Lovell DF, et al. Effects of long-term etanercept treatment on growth in children with selected categories of juvenile rheumatoid arthritis. Arthritis Rheum. 2010;62(11):3259-3264.

56. Billiau AD, Loop M, Le PQ, et al. Etanercept improves linear growth and bone mass acquisition in MTX-resistant polyarticular-course juvenile idiopathic arthritis. Rheumatology (Oxford). 2010;49(8):1550-1558.

57. Burnett HF, Regier DA, Feldman BM, Miller FA, Ungar WJ. Parents' preferences for drug treatments in juvenile idiopathic arthritis: a discrete choice experiment. Arthritis Care Res (Hoboken). 2012;64(9): 1382-1391.

\section{Publish your work in this journal}

Adolescent Health, Medicine and Therapeutics is an international, peer-reviewed, open access journal focusing on health, pathology, and treatment issues specific to the adolescent age group. All aspects of health maintenance, preventative measures and disease treatment interventions are addressed within the journal and practitioners from all disciplines are invited to submit their work as well as healthcare researchers and patient support groups. The manuscript management system is completely online and includes a very quick and fair peerreview system. Visit http://www.dovepress.com/testimonials.php to read real quotes from published authors.

Submit your manuscript here: http://www.dovepress.com/adolescent-health-medicine-and-therapeutics-journal 